\title{
A Sensitivity Analysis Approach to Identify Key Environmental Performance Factors
}

\author{
Xi Yu, ${ }^{1}$ Aicha Sekhari, ${ }^{1}$ Antoine Nongaillard, ${ }^{1}$ Abdelaziz Bouras, ${ }^{1,2}$ and Suiran $\mathbf{Y u}^{3}$ \\ ${ }^{1}$ DISP Laboratory, Lumière University Lyon 2, 160 boulevard de l'Université, 69676 Bron Cedex, France \\ ${ }^{2}$ Computer Science Department, Faculty of Engineering, Qatar University and ictQATAR, P.O. Box 2731, Doha, Qatar \\ ${ }^{3}$ School of Mechanical and Power Engineering, Shanghai Jiao Tong University, 800 Dongchuan Road, Shanghai 200240, China \\ Correspondence should be addressed to Xi Yu; xi.yu@univ-lyon2.fr
}

Received 12 November 2013; Revised 10 February 2014; Accepted 24 February 2014; Published 30 March 2014

Academic Editor: Panos Liatsis

Copyright (c) $2014 \mathrm{Xi}$ Yu et al. This is an open access article distributed under the Creative Commons Attribution License, which permits unrestricted use, distribution, and reproduction in any medium, provided the original work is properly cited.

\begin{abstract}
Life cycle assessment (LCA) is widely used in design phase to reduce the product's environmental impacts through the whole product life cycle (PLC) during the last two decades. The traditional LCA is restricted to assessing the environmental impacts of a product and the results cannot reflect the effects of changes within the life cycle. In order to improve the quality of ecodesign, it is a growing need to develop an approach which can reflect the changes between the design parameters and product's environmental impacts. A sensitivity analysis approach based on LCA and ecodesign is proposed in this paper. The key environmental performance factors which have significant influence on the products' environmental impacts can be identified by analyzing the relationship between environmental impacts and the design parameters. Users without much environmental knowledge can use this approach to determine which design parameter should be first considered when (re)designing a product. A printed circuit board (PCB) case study is conducted; eight design parameters are chosen to be analyzed by our approach. The result shows that the carbon dioxide emission during the PCB manufacture is highly sensitive to the area of PCB panel.
\end{abstract}

\section{Introduction}

Environmental issues are increasingly important for companies than ever. During the last two decades, many regulations and norms have been enacted to enforce companies to improve the environmental performance of their products. On the other hand, companies have a strong will to make environmentally friendly product in order to meet customer and market requirements and thus to earn more benefits. However, the environmental impacts reduction is a complex issue. During the whole life cycle of a product, resources are consumed and environmental releases are generated at each phase of this life cycle (e.g., design, raw material extraction, manufacturing, transportation, using, or end of life (EOL)). Therefore, environmentally friendly actions taken in different phases can all reduce the global environmental impacts of product. In order to get the best performance at the least cost, companies need to choose the best time in the life cycle to take environmentally friendly actions. [1] claims that the environmental impacts generated during the design phase represent no more than $10 \%$ of the total environmental impacts of a product. However, the decisions made at this phase lead to $70 \%$ of the total environmental impacts of a product. Many ecodesign methods have been proposed in the literature [2-7]. Indeed, the design phase plays a crucial role in the reduction of product's environmental impacts. Some methods use qualitative or semiqualitative techniques such as Eco-matrix, Checklist, and guidelines, whereas other methods are based on quantitative techniques such as ecoparametric tools and life cycle assessment (LCA).

Ecodesign methods help designers to consider the environmental issues related to a product during the design phase. However, the evaluation and the solution of the environmental issues of products are very complex tasks and need much environmental knowledge. Indeed, designers have difficulties in estimating the impact of each design parameter on the environmental performance of the product [8]. For example, a product has usually dozens of design parameters. In order to improve the environmental performance of this product, the designer has to identify which parameters would lead to 
a large improvement of its environmental performance. This task is till a big challenge so far.

This paper presents a method combining parametric design method with LCA. By assuming the relationship among the relevant economical flows (the term "economic flows" represents the materials/energy flows or commodity flows within the economic systems [9]) in LCI (life cycle inventory), the association between environmental impacts and design parameters is analyzed based on sensitivity analysis. The method proposed in this paper will help designers to quickly identify the key environmental performance factors among numerous design parameters without much environmental knowledge and thus make ecodesign more feasible in practice.

This paper is organized as follows. Section 2 describes the related works; Section 3's details introduce the proposed sensitivity analysis approach and then a case study is conducted in Section 4 to illustrate this approach. Finally, some conclusions are presented and discussed in Section 5.

\section{Literature Review}

Eco-matrix methods such as MET matrix (Material Energy Toxic) [2] or ERPA matrix (Environmentally Responsible Product Assessment) [3] may be quantitative or semiqualitative. These simplified assessment methods do not suffer from too many restrictions since detailed data on the product are not required. The required data are generally limited to physical dimensions such as the mass of the materials composing the product or the energy consumption. The manipulation of these methods implies that the user must be environmental experts who have sound knowledge on the related industrial sector.

The method of Checklist can mark the performance of a product; it relies on the listing of questions that enterprises are expected to answer $[4,5]$. By answering the questions in the checklist, several reference systems are generated for comparing with other solutions. This method is thus as a tool for helping in redesigning. However, it has not reached the step of environmental assessment yet.

Guidelines such as Ten Golden Rules [6] are widely used tools for ecodesign. Many general "universal” rules for ecodesign are collected in these methods which are easily applicable. However, these methods should be applied by people with minimum environmental knowledge. Above all, they must be supported and assisted by selected solutions, for example, material's databases.

LCA may be the best known quantitative method for environmental performance evaluation. It is a tool to assess the potential environmental impacts and resources used throughout a product's life cycle, that is, from raw material extraction, via manufacturing, transportation, and use phases, to EOL [7]. The framework of LCA described in ISO 14040, illustrated in Figure 1, is composed of four stages. In the first stage, the goal and scope are defined to guide the assessment. The second stage is the vital part. The LCI which includes the flows comes from and release to nature of a product system is compiled. The LCI includes inputs of water, energy, and raw materials and releases to air, land, and water.

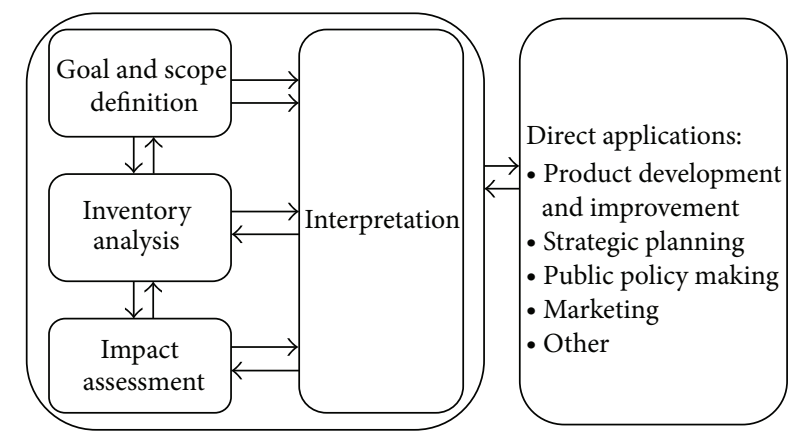

FIGURE 1: Stages of the LCA.

In the third stage, the potential environmental impacts of these inventory flows are calculated. In the last stage, the interpretation is given based on the results of each stage. Although LCA is a powerful tool to assess the environmental impacts of products, it is difficult to deploy in companies since it requires too much time to collect the related data in each phase of life cycle. And environmental expertise is needed during the entire assessment.

All the aforementioned methods are not focused on the parameter design and cannot identify which parameters need to be chosen to improve the environmental performance. They need designers to have a high level of expertise about environmental knowledge to choose proper design parameters. However, the environmental culture is complex and inadequate in companies so far. How to help designers without much environmental knowledge to design an environmentally friendly product becomes a big challenge nowadays. The parametric design method is introduced into the design phase, also called ecoparametric design, and implemented in electronic and architecture industry already. The following paragraphs discuss several studies using this method.

In order to establish an energy-saving strategy for microdrilling in PCB manufacturing, researchers like those in [10] study the parameters of the drilling process. The rotational speed of the spindle and in-feed were controlled, and the energy consumption of each process were measured. On the basis of the experiment, an energy cost model which reveals the relationship between process parameters and total energy consuming of drilling process is proposed. The key variables which can significantly influence the energy consumption of the drilling process are identified. However, due to the lack of experimental data, which make an analysis of the energy cost for the entire manufacturing process impossible now, the authors focus only on the microdrilling process.

Siddhaye and Sheng analyzed the PCB manufacturing processes and proposed a series of parametric models [11]. Based on these models, they studied the link between waste emissions and energy consumption during the manufacturing process with parameters in product design [12]. Then the formulas which reveal the relationship between waste generation and PCB parameters are proposed. However, the PCB parameters investigated in the formulas are subjective which, based on the authors' own experience, cannot help 
users to identify which design parameter has the most significant influence to improve the environmental performance of a product. In 2000, Siddhaye and Sheng proposed a sensitivity analysis (SA) approach to reveal the relationship between environmental impact and design parameters in PCB manufacturing [8]. A four-layer sensitivity diagram is proposed, as shown in Figure 2. It clearly reveals the functions between design variables, product characteristic variables, waste variables, and environmental characteristic variables. On the basis of this diagram and a series of processes models, the influence of the mass of waste by the variation of design parameters is investigated. Finally, health hazard score (HHS) evaluation is used to analyze the environmental impacts brought by the waste streams. Indeed, Siddhaye and Sheng only proposed an outline to combine the design parameters with environmental impact in their model; the detailed steps are not provided. Meanwhile, the HHS only focuses on the health hazard. However, considering the complexity of environmental issues, such a model has to be extended to other environmental fields.

A model which can design the healthcare building to support both healthy environment and building energy efficiency is proposed [13]. This model integrates a parametric design method with building information modeling (BIM) which can generate and manage the digital representations of physical and functional characteristics of places. The authors focus on improving the indoor air quality to achieve the goal of the environmental improvement and energy efficiency of the healthcare building. The parameters relevant to healthcare and sustainability are derived from the database of BIM. On the basis of a BIM authoring software, Autodesk Revit Architecture 2010, the interactive response to internal or external stimuli can be displayed. However, the parametric model provided by the BIM software was still not mature enough; the quality of the environmental data collected from it will influence the final result. This model can only deal with the environmental issues related to human health and cannot extend to other sustainable aspects.

\section{The Sensitivity Analysis Approach to Identify the Key Environmental Performance Factor}

Considering the gap between the increasing requirements of environmentally friendly products and the lack of environmental knowledge for the designers, the ecoparametric method is effective to fill the gap. The existing studies about ecoparametric methods are still not compatible with LCA which is the most popular method in environmental assessment field. The model proposed in this section integrates the parametric methods with LCA and can quickly find out which design parameter can reduce the environmental release of product in a significant way. On the basis of the new model, a sensitivity analysis approach is proposed to help users to find out the design parameter which has the most significant influence on the environmental performance of the product.

Firstly, the computation model of LCA is discussed to find out the proper way to combine the LCA with parametric

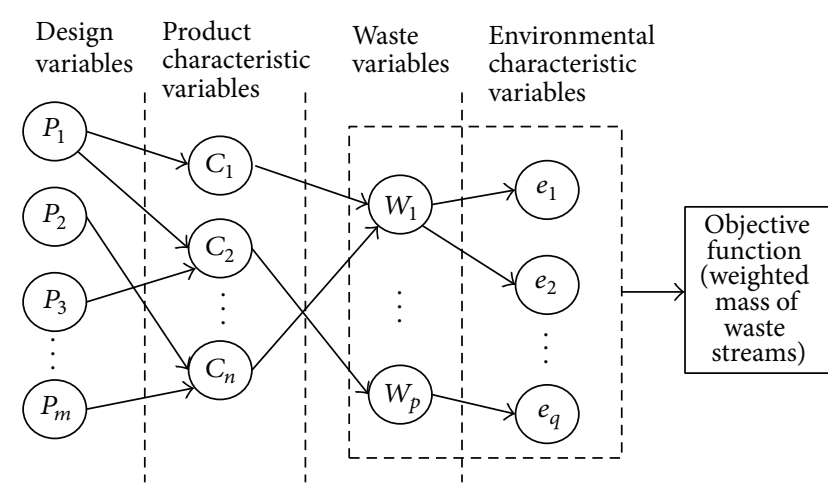

FIGURE 2: Four-layer sensitivity diagram for hazard evaluation.

model. Heijungs [14] introduced the matrix inversion method in 1994 to calculate and identify dominant aspects in the environmental load of a product. The whole product life cycle can be defined by a series of unit processes which can be denoted by a matrix $P$ as shown in formula (1). This matrix can be divided into two parts. The upper portion is called technology matrix $A$ and is composed of economic flows: $a_{i j}$ represents inflows or outflows of commodity $i$ of process $j$ for certain duration of process operation (inflows and outflows are, respectively, denoted by negative and positive values). The lower portion is called intervention matrix $B$ and is composed of environmental flows: the entry $b_{i j}$ represents the amount of pollutants or natural resources $i$ emitted or consumed by the process $j$

$$
P=\left(\frac{A}{B}\right)=\left(\begin{array}{cccc}
a_{11} & a_{12} & \cdots & a_{1 n} \\
a_{21} & a_{21} & & a_{2 n} \\
\vdots & & & \vdots \\
a_{n 1} & a_{n 2} & \cdots & a_{n n} \\
\hline b_{11} & b_{12} & \cdots & b_{1 n} \\
\vdots & & & \vdots \\
b_{i 1} & b_{i 2} & \cdots & b_{i n}
\end{array}\right)
$$

The function unit of the product is chosen during LCA. The final demand vector corresponds to the function unit and can be denoted by the reference flow $f$. The final demand vector is an exogenously defined set of economic flows which produces by the system at exactly the given amount. When producing this final demand, the environmental release is produced at the same time. The vector $g$ is used to represent the environmental release according to the final demand:

$$
g=\left(\begin{array}{lll}
g_{1} & \cdots & g_{i}
\end{array}\right)^{T}
$$

In order to calculate the environmental release $g$, a vector with scaling factors $s$ is introduced. Each entry of a column vector $s$ denotes the required process scaling factors of each process to produce the required output $(f)$ of the system. The commodity net output or final demand vector of the system is given by

$$
f=A \times s .
$$


Formula (3) represents the fact that the amount of a commodity produced from a system is equal to the amount produced in each unit process multiple scale factors. Rearranging formula (3), the total scaling factors $s$ required to meet the total commodity net output $f$ can be calculated by

$$
s=A^{-1} f
$$

On the basis of the technology matrix, the intervention matrix, and the final demand vector, the total pollutant emissions and natural resources consumption by the system to produce a certain amount of commodity output are calculated by [15]

$$
g=B A^{-1} f
$$

In order to investigate the environmental effects due to the mass of materials/energies used in the system, Heijungs and Suh propose a sensitivity analysis method to calculate the influence of variation in matrix $A$ [9]. The relationship between the changes of entry $a_{i j}$ and the changes of $g_{k}$ can be represented by

$$
\frac{\partial g_{k}}{\partial a_{i j}}=-\left(B A^{-1}\right)_{k i} s_{j}
$$

Formula (6) can help the designers to find out which material has significant influence on the final environmental release. However, the mass of material used in a unit process usually depends on several design parameters. For example, the weight of a glass cup can be decided by the thickness, the diameter, and the height of the cup. If the final environmental release is mostly decided by the weight of the glass, the design parameter that should be chosen to adjust represents the key for environmental oriented design.

In the existing studies on LCA, the relationship between the mass of materials/energies used in each process of product life cycle and the environmental release is the basis to compile the LCI. Generally, the relationship can be illustrated by

$$
g_{k}=F\left(a_{11}, a_{12}, \ldots, a_{n n}\right) .
$$

$F$ denotes that $g_{k}$ is a function of $a_{i j}$. However, this function cannot help users to find out the relationship between the mass of materials/energies using in each process and design parameters.

The joint point of LCA and parametric model is revealed by formula (7). If the parametric model can be represented as the following formula, then the parametric model can be integrated into LCA computation:

$$
a_{i j}=T_{k}\left(d_{1}, d_{2}, \ldots, d_{m}\right) \text {. }
$$

$T_{k}$ denotes the function of $a_{i j}$ and $d_{m}$ and vector $d$ denotes the design parameters. For example, Siddhaye and Sheng proposed a parametric model in PCB manufacturing [11]. The following equations are two models which can help users to calculate the solid waste stream during the composite lamination process:

$$
\begin{aligned}
m_{\mathrm{Cu}}= & \rho_{\mathrm{Cu}}\left\{\left[\left(A_{\text {core }}-A_{\text {panel }}\right) \sum_{i=2}^{i=N_{\text {layers }}-1} t_{i-\mathrm{Cu}}\right]\right. \\
& \left.+2\left(A_{\mathrm{Cu}}-A_{\text {panel }}\right) t_{\mathrm{Cu}}\right\}, \\
m_{\text {pre-preg }}= & \rho_{\text {pre-preg }} t_{\text {pre-preg }} \\
& \times\left\{\left(\frac{N_{\text {layers }}}{2}-1\right)\left(A_{\text {core }}-A_{\text {panel }}\right)\right. \\
& \left.+N_{\text {pre-preg }}\left(A_{\text {pre-preg }}-A_{\text {panel }}\right)\right\} .
\end{aligned}
$$

$N_{\text {pre-preg }}$ denotes the number of prepreg sheets added per panel. $t_{\mathrm{Cu}}$ and $A_{\mathrm{Cu}}$ denote the average thickness and area of the copper foil added on top and bottom forming outer layers, respectively. $t_{\text {pre-preg }}$ denotes the thickness of each sheet, and $A_{\text {pre-preg }}$ denotes the area of each sheet. $N_{\text {layers }}$ denotes the total number of layers of the board, and $A_{\text {panel }}$ is the area of the trimmed panel.

The LCA method cannot let designers choose proper design parameters based on the results because it does not reveal the relationship between design parameters and the environmental impacts. Moreover, parametric design model cannot assess the product's environmental impacts since it only focuses on the relationship between mass of materials/energies and design parameters. To eliminate the disadvantage of the LCA method and parametric model and build up the relationship between design parameters and the environmental impacts, the integration of LCA and parametric model can be conducted by substituting formula (8) into formula (6) as shown in

$$
-\left(B A^{-1}\right)_{k i} s_{j}=\frac{\partial g_{k}}{\partial a_{i j}}=\frac{\partial g_{k}}{\partial T_{k}\left(d_{1}, d_{2}, \ldots, d_{m}\right)} .
$$

On the basis of the integration, the analysis of which parameter has the most significant influence on environmental impacts becomes possible. A sensitivity analysis approach is proposed based on the above analysis and the advantage of this approach can calculate the influence of $g_{k}$ according to the variation of $d_{m}$ :

$$
\begin{aligned}
\frac{\partial g_{k}}{\partial d_{m}}= & \frac{\partial F\left(a_{11}, a_{12}, \ldots, a_{n n}\right)}{\partial d_{m}} \\
= & \left(\partial F \left(T_{1}\left(d_{1}, d_{2}, \ldots, d_{m}\right),\right.\right. \\
& \left.\left.T_{2}\left(d_{1}, d_{2}, \ldots, d_{m}\right) \ldots T_{k}\left(d_{1}, d_{2}, \ldots, d_{m}\right)\right)\right) \\
& \times\left(\partial d_{m}\right)^{-1}=\frac{\partial F\left(a_{11}\right)}{\partial a_{11}} \frac{\partial T_{1}\left(d_{1}, d_{2}, \ldots, d_{m}\right)}{\partial d_{m}} \\
& +\frac{\partial F\left(a_{12}\right)}{\partial a_{12}} \frac{\partial T_{2}\left(d_{1}, d_{2}, \ldots, d_{m}\right)}{\partial d_{m}}
\end{aligned}
$$




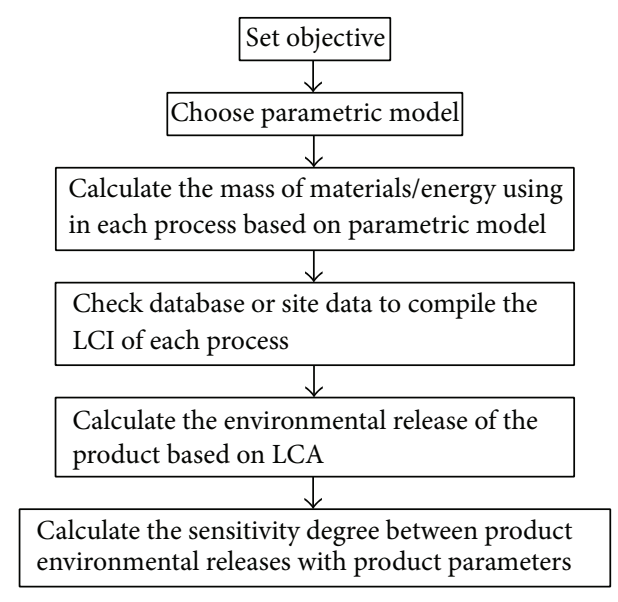

FIgURE 3: The process steps of the model.

$$
\begin{aligned}
& +\cdots+\frac{\partial F\left(a_{n n}\right)}{\partial a_{n n}} \frac{\partial T_{k}\left(d_{1}, d_{2}, \ldots, d_{m}\right)}{\partial d_{m}} \\
= & \sum_{\substack{i=1 \\
j=n \\
j=1}}^{\substack{j=n \\
j=1}}\left(\frac{\partial g_{k}}{\partial a_{i j}} \times \frac{\partial a_{i j}}{\partial d_{m}}\right) .
\end{aligned}
$$

On the basis of formula (6),

$$
\frac{\partial g_{k}}{\partial d_{m}}=\sum_{\substack{i=1 \\ j=1}}^{\substack{i=n \\ j=n}}-\left(B A^{-1}\right)_{k i} \times s_{j} \times \frac{\partial a_{i j}}{\partial d_{m}}
$$

The value of $\partial g_{k} / \partial d_{m}$ is the indicator for the designer to reduce the value of $g_{k}$. On the basis of the value of the indicator, designers can easily find out which design parameter's variation can influence the special environmental release significantly. During the whole process, designers do not need to have much environmental knowledge.

In practice, the steps as shown in Figure 3 can be used to conduct a case study.

\section{Case Study}

Nowadays, with the development of microprocessor technologies, increasing numbers of electronic devices are used in daily life [16]. Due to these devices, the environmental pollution becomes acutely severe. Printed circuit boards are the fundamental component of an electronic device. According to the statistic report of IPC (Association Connecting Electronics Industries) in 2012 [17], the production value of PCB is over $\$ 60$ billion. However, each phase of the PCBs life cycle brings serious environmental impacts because of their chemical and physical characteristic. Therefore, environment-oriented design of PCB should be studied carefully.

Based on the existing studies $[11,18,19]$, the general processes of the PCB life cycle are described in Figure 4.

The manufacturing processes of PCB are complex. Enterprises use large amounts of chemical materials generating numerous types of hazardous wastes. These wastes are potentially harmful to the environment and human health [20, 21]. In this case study, the carbon dioxide emission is used as an indicator to compare different effects of the different design solutions.

The mass of waste generated during the PCB manufacturing can be calculated by the parametric model of PCB proposed by Siddhaye and Sheng [11]. Although this model was proposed twenty years ago, it still works in many enterprises in China [22-24].

In order to correspond with the symbols defined in our model, all parameters are denoted by $d_{m}$. This case study focuses on a four-layer PCB. The main design parameters are the copper's thickness in each layer, the copper's proportion of each layer, the area of PCB panel, and the area of PCB core. The original design parameters values are described in Table 1 .

The manufacturing of PCB needs many processes. In this case study, the masses of prepreg, copper, electricity, waste prepreg, and waste copper are taken into account to evaluate the environmental issues of PCB. The processes related to these materials are investigated. On the basis of the parametric model proposed by [11], the mass of materials using in each process is obtained. Then, by checking "the standard of clean manufacture-PCB industry in China" and ecoinvent database, the environmental release of each process for the original design parameters can be acquired. The main process in a PCB manufacture system is illustrated in Table 2.

The first 9 rows of Table 2 constitute the economic matrix $A$ and the last 3 rows comprise the environmental matrix $B$. This table is represented by the use of a matrix form:

$$
P=\left(\frac{A}{B}\right)=\left(\begin{array}{ccccccccc}
1000 & 0 & 0 & -320.61 & 0 & 0 & 0 & 0 & 0 \\
0 & 1000 & 0 & -410.89 & 0 & 0 & 0 & 0 & 0 \\
0 & 0 & 1 & -68.7 & -22.9 & -45.8 & -91.6 & 0 & 0 \\
0 & 0 & 0 & 1 & -1 & 0 & 0 & 0 & 0 \\
0 & 0 & 0 & 0 & 1 & -1 & 0 & 0 & 0 \\
0 & 0 & 0 & 0 & 0 & 1 & -1 & 0 & 0 \\
0 & 0 & 0 & 0 & 0 & 0 & 1 & 0 & 0 \\
0 & 0 & 0 & 13.33 & 0 & 36.35 & 0 & 1000 & 0 \\
0 & 0 & 0 & 18.63 & 6.77 & 10.97 & 35.52 & 0 & 1000 \\
\hline 4160 & 376 & 134 & 132.27 & 52.9 & 52.9 & 26.45 & 2100 & 2300 \\
144 & 141 & 59.8 & 5.856 & 2.3424 & 2.3424 & 1.1712 & 120 & 78 \\
215 & 115 & 22.3 & 1.654 & 0.6256 & 0.6256 & 0.3128 & 105 & 80
\end{array}\right) .
$$


TABLE 1: The original value of each design parameter (Siddhaye and Sheng, 1997 [11]).

\begin{tabular}{lccccc}
\hline Parameter's meaning & $\begin{array}{c}\text { Copper's } \\
\text { thickness in } \\
\text { layer 1 }\end{array}$ & $\begin{array}{c}\text { Copper's } \\
\text { thickness in } \\
\text { layer 2 }\end{array}$ & $\begin{array}{c}\text { Copper's } \\
\text { thickness in } \\
\text { layer 3 }\end{array}$ & $\begin{array}{c}\text { Copper's } \\
\text { thickness in } \\
\text { layer 4 }\end{array}$ & $\begin{array}{c}\text { Copper's } \\
\text { proportion in } \\
\text { layer 1 }\end{array}$ \\
\hline Parameter's symbol & $d_{1}$ & $d_{2}$ & $d_{3}$ & $d_{4}$ & 0.6 \\
\hline Parameter's value & 0.6 & 2.4 & 1.2 & $d_{5}$ & 0.611 \\
\hline Parameter's meaning & $\begin{array}{c}\text { Copper's } \\
\text { proportion in } \\
\text { layer 2 }\end{array}$ & $\begin{array}{c}\text { Copper's } \\
\text { proportion in } \\
\text { layer 3 }\end{array}$ & $\begin{array}{c}\text { Copper's } \\
\text { proportion in } \\
\text { layer 4 }\end{array}$ & $\begin{array}{c}\text { Area of PCB } \\
\text { panel }\end{array}$ & $\begin{array}{c}\text { Area of PCB } \\
\text { core }\end{array}$ \\
\hline Parameter's symbol & $d_{6}$ & $d_{7}$ & $d_{8}$ & $d_{9}$ & 0.321935 \\
\hline Parameter's value & 0.940 & 0.970 & 0.581 & & $d_{10}$ \\
\hline
\end{tabular}

TABLE 2: The economic and environmental information of a PCB manufacture system.

\begin{tabular}{|c|c|c|c|c|c|c|c|c|c|}
\hline Commodity & $\begin{array}{c}\text { Production } \\
\text { of prepreg }\end{array}$ & $\begin{array}{c}\text { Production } \\
\text { of copper }\end{array}$ & $\begin{array}{l}\text { Production } \\
\text { of electricity }\end{array}$ & $\begin{array}{c}\text { Core } \\
\text { lamination }\end{array}$ & Etch & $\begin{array}{c}\text { Hole } \\
\text { desmear }\end{array}$ & $\begin{array}{c}\text { Production } \\
\text { of PCB }\end{array}$ & $\begin{array}{l}\text { Production of } \\
\text { waste prepreg }\end{array}$ & $\begin{array}{c}\text { Production of } \\
\text { waste copper }\end{array}$ \\
\hline g prepreg & 1000 & 0 & 0 & -320.61 & 0 & 0 & 0 & 0 & 0 \\
\hline g copper & 0 & 1000 & 0 & -410.89 & 0 & 0 & 0 & 0 & 0 \\
\hline MJ electricity & 0 & 0 & 1 & -68.7 & -22.9 & -45.8 & -91.6 & 0 & 0 \\
\hline $\mathrm{m}^{2}$ bared $\mathrm{PCB}$ & 0 & 0 & 0 & 1 & -1 & 0 & 0 & 0 & 0 \\
\hline $\mathrm{m}^{2}$ etched board & 0 & 0 & 0 & 0 & 1 & -1 & 0 & 0 & 0 \\
\hline $\mathrm{m}^{2}$ holed board & 0 & 0 & 0 & 0 & 0 & 1 & -1 & 0 & 0 \\
\hline $\mathrm{m}^{2} \mathrm{PCB}$ & 0 & 0 & 0 & 0 & 0 & 0 & 1 & 0 & 0 \\
\hline g waste prepreg & 0 & 0 & 0 & 13.33 & 0 & 36.35 & 0 & 1000 & 0 \\
\hline g waste copper & 0 & 0 & 0 & 18.63 & 6.77 & 10.97 & 35.52 & 0 & 1000 \\
\hline g carbon dioxide & 4160 & 376 & 134 & 132.27 & 52.9 & 52.9 & 26.45 & 2100 & 2300 \\
\hline g sulfur & 144 & 141 & 59.8 & 5.856 & 2.3424 & 2.3424 & 1.1712 & 120 & 78 \\
\hline g nitrogen & 215 & 115 & 22.3 & 1.654 & 0.6256 & 0.6256 & 0.3128 & 105 & 80 \\
\hline
\end{tabular}

Assume that the final demand of the system is to produce $1 \mathrm{~m}^{2}$ PCB board; then it can be represented by vector $f=$ $\left(\begin{array}{lllllllll}0 & 0 & 0 & 0 & 0 & 0 & 1 & 0 & 0\end{array}\right)^{T}$.

On the basis of matrix-based LCA computational method, the environmental release of the final demand is $g=\left(\begin{array}{lll}32169.08 & 13798.45 & 5215.13\end{array}\right)^{T} \cdot g_{1}$ denotes the carbon dioxide emission, $g_{2}$ denotes the sulfur release, and $g_{3}$ denotes nitrogen release.

Using (12), the sensitivity degree between design parameters and carbon dioxide emission can be determined as shown in Table 3.

According to these sensitivity degrees, the most sensitive parameter to the carbon dioxide emission is the area of PCB panel $d_{9}$, while the most insensitive parameter is the copper's proportion in layer $4 d_{8}$. Then, the designers can quickly identify the fact that the key environmental performance factor which has a significant influence on the carbon dioxide emission is the value of the area of PCB panel.

In order to verify the results, the values of these five parameters are adjusted according to the design constraints and the carbon dioxide emission is recalculated.
By changing $d_{1}$ from 0.6 to 0.62 , the materials used in each process are

$$
\mathrm{A}=\left(\begin{array}{ccccccccc}
1000 & 0 & 0 & -320.61 & 0 & 0 & 0 & 0 & 0 \\
0 & 1000 & 0 & -419.45 & 0 & 0 & 0 & 0 & 0 \\
0 & 0 & 1 & -68.7 & -22.9 & -45.8 & -91.6 & 0 & 0 \\
0 & 0 & 0 & 1 & -1 & 0 & 0 & 0 & 0 \\
0 & 0 & 0 & 0 & 1 & -1 & 0 & 0 & 0 \\
0 & 0 & 0 & 0 & 0 & 1 & -1 & 0 & 0 \\
0 & 0 & 0 & 0 & 0 & 0 & 1 & 0 & 0 \\
0 & 0 & 0 & 13.33 & 0 & 36.35 & 0 & 1000 & 0 \\
0 & 0 & 0 & 18.63 & 6.77 & 11.59 & 38.48 & 0 & 1000
\end{array}\right) .
$$

The reference flow is $g=\left(\begin{array}{llll}32164.06 & 13799.37 & 5215.83\end{array}\right)^{T}$ and the carbon dioxide emission $g_{1}$ is $32164.06 \mathrm{~g}$. Compared with the original design, the carbon dioxide emission $g_{1}$ is reduced by 5.02 . 
TABLE 3: Sensitivity degree between design parameters and carbon dioxide emission.

\begin{tabular}{|c|c|c|c|c|c|c|c|c|c|c|}
\hline & $d_{1}$ & $d_{2}$ & $d_{3}$ & $d_{4}$ & $d_{5}$ & $d_{6}$ & $d_{7}$ & $d_{8}$ & $d_{9}$ & $d_{10}$ \\
\hline Carbon dioxide emission & -437.68 & -379.02 & -376.43 & -437.68 & 94.83 & 207.69 & 103.85 & 94.83 & 3449.13 & 464.06 \\
\hline
\end{tabular}

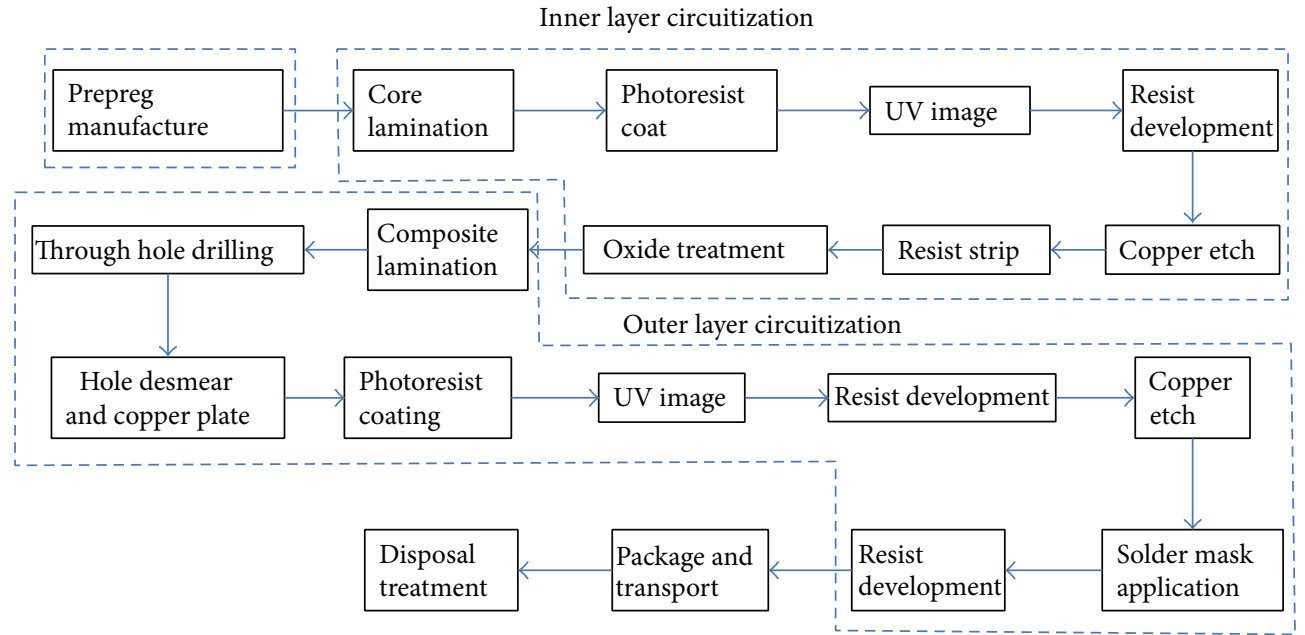

Process steps in printed circuit board fabrication

FIgure 4: Processes steps in PCB life cycle.

By changing $d_{6}$ from 0.940 to 0.920 , the materials used in each process are

$\mathrm{A}=\left(\begin{array}{ccccccccc}1000 & 0 & 0 & -320.61 & 0 & 0 & 0 & 0 & 0 \\ 0 & 1000 & 0 & -410.89 & 0 & 0 & 0 & 0 & 0 \\ 0 & 0 & 1 & -68.7 & -22.9 & -45.8 & -91.6 & 0 & 0 \\ 0 & 0 & 0 & 1 & -1 & 0 & 0 & 0 & 0 \\ 0 & 0 & 0 & 0 & 1 & -1 & 0 & 0 & 0 \\ 0 & 0 & 0 & 0 & 0 & 1 & -1 & 0 & 0 \\ 0 & 0 & 0 & 0 & 0 & 0 & 1 & 0 & 0 \\ 0 & 0 & 0 & 13.33 & 0 & 36.35 & 0 & 1000 & 0 \\ 0 & 0 & 0 & 18.63 & 8.58 & 10.97 & 35.52 & 0 & 1000\end{array}\right)$.

The reference flow is $g=\left(\begin{array}{lll}32164.91 & 13798.31 & 5214.99\end{array}\right)^{T}$ and the carbon dioxide emission $g_{1}$ is $32164.91 \mathrm{~g}$. Compared with the original design, the carbon dioxide emission $g_{1}$ is reduced by 4.17 .

By changing $d_{8}$ from 0.581 to 0.561 , the materials used in each process are

$\mathrm{A}=\left(\begin{array}{ccccccccc}1000 & 0 & 0 & -320.61 & 0 & 0 & 0 & 0 & 0 \\ 0 & 1000 & 0 & -410.89 & 0 & 0 & 0 & 0 & 0 \\ 0 & 0 & 1 & -68.7 & -22.9 & -45.8 & -91.6 & 0 & 0 \\ 0 & 0 & 0 & 1 & -1 & 0 & 0 & 0 & 0 \\ 0 & 0 & 0 & 0 & 1 & -1 & 0 & 0 & 0 \\ 0 & 0 & 0 & 0 & 0 & 1 & -1 & 0 & 0 \\ 0 & 0 & 0 & 0 & 0 & 0 & 1 & 0 & 0 \\ 0 & 0 & 0 & 13.33 & 0 & 36.35 & 0 & 1000 & 0 \\ 0 & 0 & 0 & 18.63 & 6.77 & 10.97 & 36.40 & 0 & 1000\end{array}\right)$

The reference flow is $g=\left(\begin{array}{lll}32167.05 & 13798.38 & 5215.06\end{array}\right)^{T}$ and the carbon dioxide emission $g_{1}$ is $32167.05 \mathrm{~g}$. Compared with the original design, the carbon dioxide emission $g_{1}$ is reduced by 2.03 .
By changing $d_{9}$ from 0.321935 to 0.301935 , the materials used in each process are

$$
\mathrm{A}=\left(\begin{array}{ccccccccc}
1000 & 0 & 0 & -320.61 & 0 & 0 & 0 & 0 & 0 \\
0 & 1000 & 0 & -410.89 & 0 & 0 & 0 & 0 & 0 \\
0 & 0 & 1 & -68.7 & -22.9 & -45.8 & -91.6 & 0 & 0 \\
0 & 0 & 0 & 1 & -1 & 0 & 0 & 0 & 0 \\
0 & 0 & 0 & 0 & 1 & -1 & 0 & 0 & 0 \\
0 & 0 & 0 & 0 & 0 & 1 & -1 & 0 & 0 \\
0 & 0 & 0 & 0 & 0 & 0 & 1 & 0 & 0 \\
0 & 0 & 0 & 13.33 & 0 & 58.57 & 0 & 1000 & 0 \\
0 & 0 & 0 & 18.63 & 6.77 & 21.89 & 33.31 & 0 & 1000
\end{array}\right) .
$$

The reference flow is $g=\left(\begin{array}{lll}32102.38 & 13795.10 & 5212.10\end{array}\right)^{T}$ and the carbon dioxide emission $g_{1}$ is $32102.38 \mathrm{~g}$. Compared with the original design, the carbon dioxide emission $g_{1}$ is reduced by 66.70 .

By changing $d_{10}$ from 0.33065 to 0.31065 , the materials used in each process are

$$
\mathrm{A}=\left(\begin{array}{ccccccccc}
1000 & 0 & 0 & -320.61 & 0 & 0 & 0 & 0 & 0 \\
0 & 1000 & 0 & -410.89 & 0 & 0 & 0 & 0 & 0 \\
0 & 0 & 1 & -68.7 & -22.9 & -45.8 & -91.6 & 0 & 0 \\
0 & 0 & 0 & 1 & -1 & 0 & 0 & 0 & 0 \\
0 & 0 & 0 & 0 & 1 & -1 & 0 & 0 & 0 \\
0 & 0 & 0 & 0 & 0 & 1 & -1 & 0 & 0 \\
0 & 0 & 0 & 0 & 0 & 0 & 1 & 0 & 0 \\
0 & 0 & 0 & 22.22 & 0 & 31.90 & 0 & 1000 & 0 \\
0 & 0 & 0 & 26.82 & 6.36 & 2.78 & 35.52 & 0 & 1000
\end{array}\right) .
$$

The reference flow is $g=\left(\begin{array}{llll}32160.70 & 13797.95 & 5214.70\end{array}\right)^{T}$ and the carbon dioxide emission $g_{1}$ is $32160.70 \mathrm{~g}$. Compared with the original design, the carbon dioxide emission $g_{1}$ is reduced by 8.38 . 
TABLE 4: The carbon dioxide emission variation corresponding to the variation of design parameter.

\begin{tabular}{lccccc}
\hline$g_{1}$ & $d_{1}$ & $d_{6}$ & $d_{8}$ & $d_{9}$ & $d_{10}$ \\
\hline Variation value & 5.02 & 4.17 & 2.03 & 66.70 & 8.38 \\
\hline
\end{tabular}

The variation of different parameters and the result of the corresponding carbon dioxide emission are summarized in Table 4 . It proves that the area of PCB panel $d_{9}$ is the most sensitive parameter which has significant influence on the environmental performance of the PCB manufacturing.

In this case study, a PCB parametric model is integrated with LCA. By using sensitivity analysis approach, the sensitive degrees between parameters and carbon dioxide emission are investigated. In order to verify the results, the value of carbon dioxide emission according to each parameter is calculated. The result shows that our approach can effectively help designers quickly find out the key environmental performance factors without much environmental knowledge. This case study only observes the relationship between parameters with one environmental issue. However, on the basis of our approach, all the environmental issues relevant to users' objectives can be investigated. Meanwhile, the purpose of the parametric models using in this case study is to calculate the mass of waste based on design parameters. Therefore, it can be replaced by other parametric models which can reveal the relationship between the mass of materials/energies using in each process of product and the design parameters. By integrating different parametric models, our approach can be easy to extend to different industries.

\section{Conclusion}

This paper integrates the parametric design method with matrix-based LCA and then uses sensitivity analysis approach to study the relationship between design parameters and environmental performance. The analysis results show that the key environmental performance factors can be found out from numerous design parameters easily. The significant advantage of this approach is aiding designers who lack environmental knowledge to choose proper design parameters to improve the environmental performance of a product. A PCB case study based on this approach is conducted. The results clearly prove that this approach can help users find out the key environmental performance factors for the PCB manufacture accurately and quickly. In the future, the relationship between a design parameter and different environmental releases will be investigated. Then the problems will become more complex because a design parameter may have different influence effects on different environmental releases. Therefore, a decision making model needs to be constructed to help users choose the proper design parameter to improve the environmental performance based on the analysis result.

\section{Conflict of Interests}

The authors declare that there is no conflict of interests regarding the publication of this paper.

\section{Acknowledgments}

This project has been funded by support from the European Commission Project (EMA2-2010-2359) and Hubert Curien Partnership with Cai Yuanpei China program 2012-2014. This paper reflects the views of only the author, and the commission cannot be held responsible for any use which may be made of the information contained therein.

\section{References}

[1] G. Rebitzer, T. Ekvall, R. Frischknecht et al., "Life cycle assessment: part 1: framework, goal and scope definition, inventory analysis, and applications," Environment International, vol. 30, no. 5, pp. 701-720, 2004.

[2] H. Brezet, Ecodesign: A Promising Approach to Sustainable Production and Consumption, UNEP, Delft, The Netherlands, 1997.

[3] T. E. Graedel and B. R. Allenby, Design for Environment, Prentice Hall, Upper Saddle River, NJ, USA, 1996.

[4] W. Wende, A. Bond, N. Bobylev, and L. Stratmann, "Climate change mitigation and adaptation in strategic environmental assessment," Environmental Impact Assessment Review, vol. 32, no. 1, pp. 88-93, 2012.

[5] L. A. Sandham and H. M. Pretorius, "A review of EIA report quality in the North West province of South Africa," Environmental Impact Assessment Review, vol. 28, no. 4-5, pp. 229-240, 2008.

[6] C. Luttropp and J. Lagerstedt, "EcoDesign and The Ten Golden Rules: generic advice for merging environmental aspects into product development," Journal of Cleaner Production, vol. 14, no. 15-16, pp. 1396-1408, 2006.

[7] ISO14040, "Environmental management-life cycle assessment-principles and framework," Environmental Management 3, 2006.

[8] S. Siddhaye and P. Sheng, "Environmental impact and design parameters in electronics manufacturing - a sensitivity analysis approach," in Proceedings of the IEEE International Symposium on Electronics and the Environment (ISEE '00), pp. 39-45, October 2000

[9] R. Heijungs and S. Suh, The Computational Structure of Life Cycle Assessment, Springer, 2002.

[10] H. S. Yoon, B. Bhandari, J. S. Moon et al., "Energy analysis of micro-drilling process used to manufacture printed circuit boards," in Leveraging Technology for a Sustainable World, pp. 305-309, Springer, 2012.

[11] S. Siddhaye and P. Sheng, "Integration of environmental factors in process modeling for printed circuit board manufacturing, part II: fabrication," in Proceedings of the 5th IEEE International Symposium on Electronics and the Environment (ISEE '97), pp. 226-233, May 1997.

[12] S. Siddhaye and P. Sheng, "Evaluating environmental factors for pre-layout board design," in Proceedings of the IEEE International Symposium on Electronics and the Environment (ISEE' '98), pp. 99-105, May 1998.

[13] J. Wang, X. Chen, J. Li, and Z. Lv, "Developing indoor air quality through healthcare and sustainable parametric method," in Proceedings of the 4th International Conference on Bioinformatics and Biomedical Engineering (iCBBE '10), June 2010.

[14] R. Heijungs, "A generic method for the identification of options for cleaner products," Ecological Economics, vol. 10, no. 1, pp. 6981, 1994. 
[15] S. Suh and G. Huppes, "Methods for life cycle inventory of a product," Journal of Cleaner Production, vol. 13, no. 7, pp. 687697, 2005.

[16] G. Suyang and J. Liu, Life cycle assessment on Autoliv's electronic control unit [M.S. thesis], Chalmers University of Technology, 2010, master: 432.

[17] IPC, "World PCB Production Report for the Year 2012," http:// www.ipc.org/ContentPage.aspx?pageid=World-PCB-MarketGrew-in-2012.

[18] P. Worhach and P. Sheng, "Integration of environmental factors in process modeling for printed circuit board manufacturing, part I: assembly," in Proceedings of the 5th IEEE International Symposium on Electronics and the Environment (ISEE '97), pp. 218-225, May 1997.

[19] R. K. Kanth, P. Liljeberg, H. Tenhunen, Q. Wan, and L. Zheng, "Insight into quantitative environmental emission analysis of printed circuit board," in Proceedings of the 10th International Conference on Environment and Electrical Engineering (EEEIC '11), May 2011.

[20] I. K. Hui, C. P. Li, and H. C. W. Lau, "Hierarchical environmental impact evaluation of a process in printed circuit board manufacturing," International Journal of Production Research, vol. 41, no. 6, pp. 1149-1165, 2003.

[21] F. W. Kirsch, Waste Minimization Assessment for Multilayered Printed Circuit Board Manufacturing, U.S. Environmental Protection Agency, Risk Reduction Engineering Laboratory, 1991.

[22] R. Xiong, Life cycle assessment methods used to achieve cleaner production of printed circuit boards [M.S. thesis], Guangdong University of Technology, 2008.

[23] X.-X. Yang, "How to promote the cleaner production in PCB factories," Printed Circuit Information, pp. 54-60, 2010.

[24] C. Zhao, "Double sided printed circuit board hole of electrochemistry aggradation technics and wastewater quantity compute," Inner Mongolia Environmental Sciences, no. 3, pp. 163-165, 2012. 


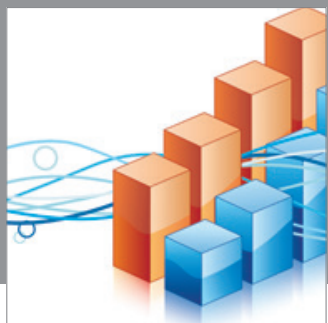

Advances in

Operations Research

mansans

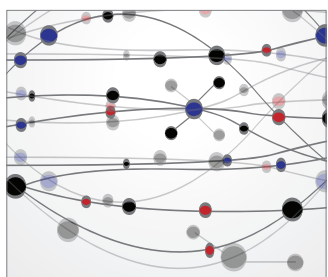

The Scientific World Journal
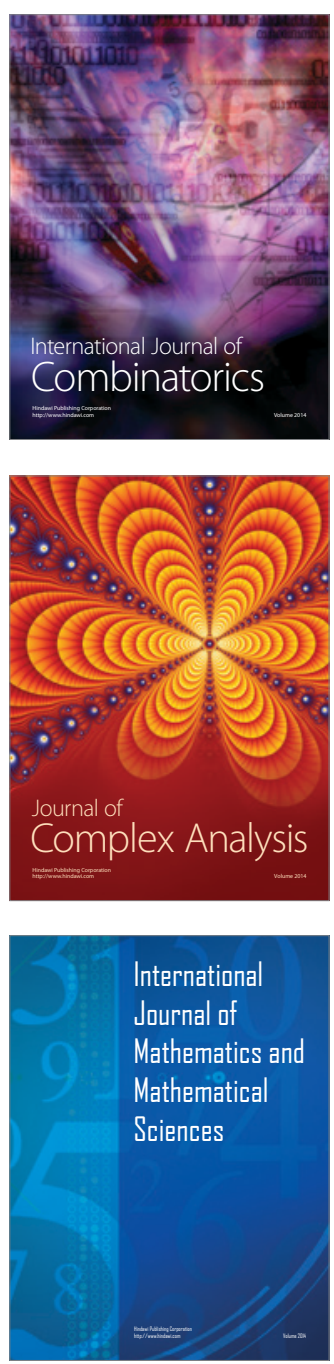
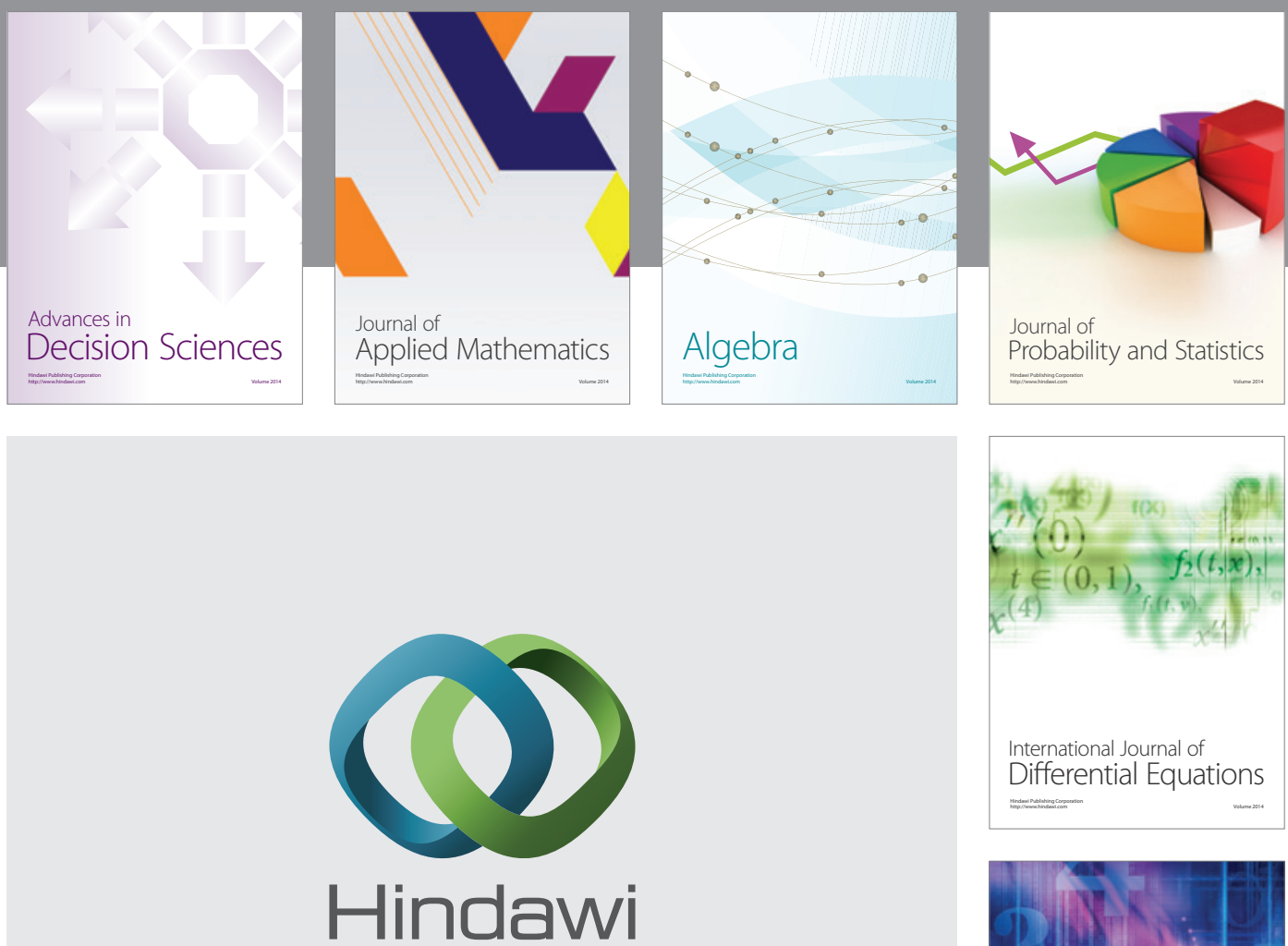

Submit your manuscripts at http://www.hindawi.com
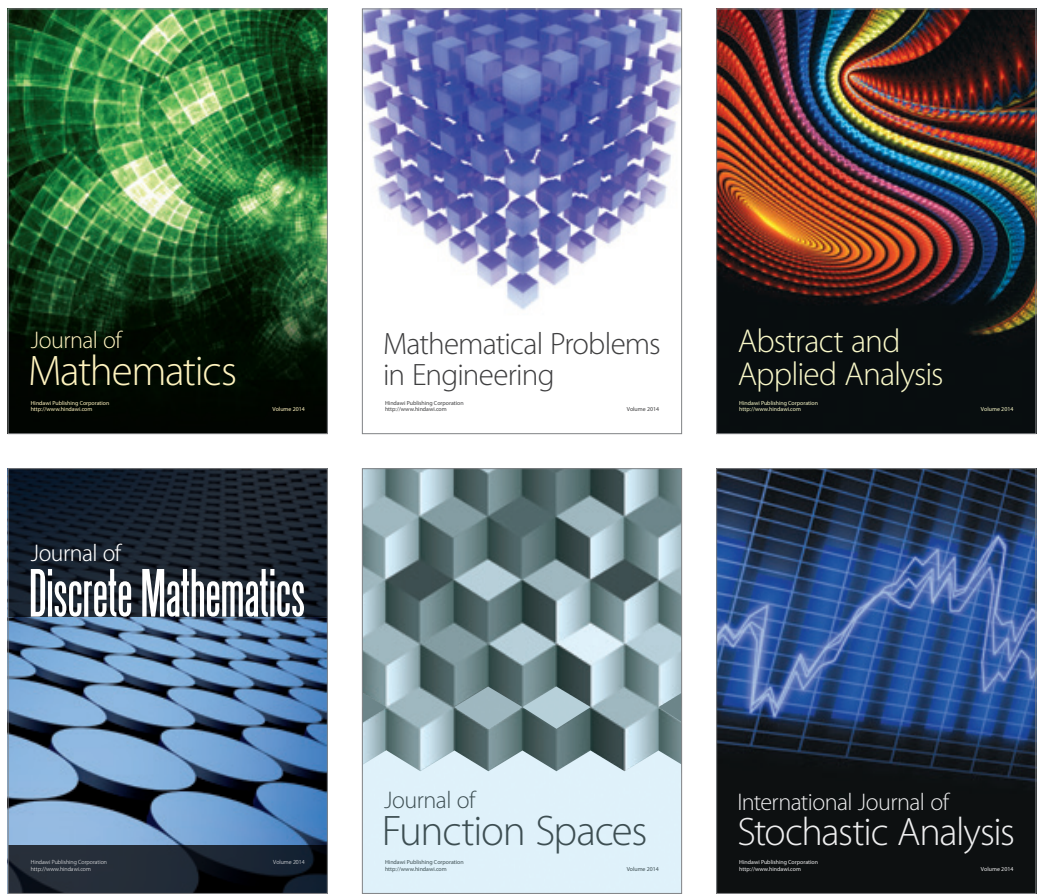

Journal of

Function Spaces

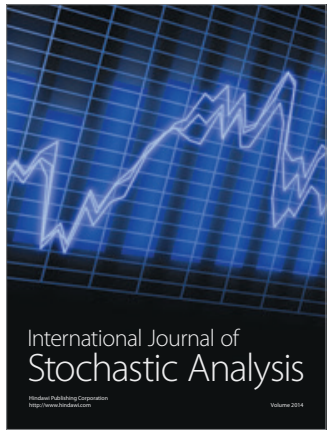

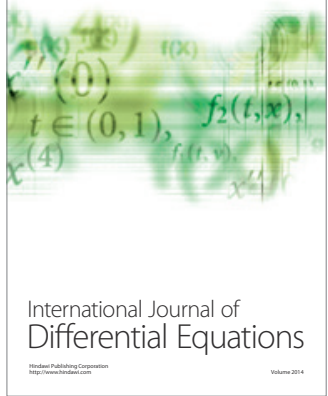
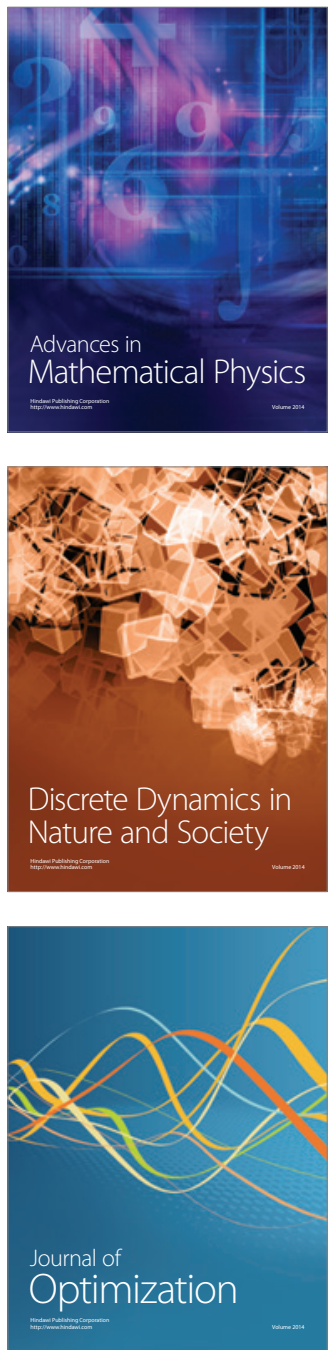